\title{
HUBUNGAN ANTARA INDEKS PRESTASI KUMULATIF DAN NILAI UJI KOMPETENSI DOKTER INDONESIA PADA DOKTER LULUSAN UNIVERSITAS TANJUNGPURA
}

\author{
Oleh : \\ Arif Wicaksono ${ }^{1}$,
}

\begin{abstract}
Abstrak
Latar belakang. Banyaknya Fakultas kedokteran yang ada di Indonesia dengan berbagai macam metode pembelajaran memerlukan standarisasi nasional untuk para lulusannya. Program Studi pendidikan Dokter (PSPD) Fakultas Kedokteran (FK) Universitas Tanjungpura telah meluluskan dokter yang diharapkan memiliki standar yang sama dengan dokter-dokter lulusan FK lain. Indeks prestasi merupakan salah satu komponen kemajuan atau prestasi belajar. Tujuan. Penelitian ini bertujuan untuk mengetahui apakah ada hubungan antara IPK dan nilai UKDI dokter lulusan UNTAN. Metode. Penelitian ini merupakan penelitian analitik cross sectional yang dilakukan selama bulan Agustus 2011 di Prodi Pendidikan Dokter FKIK UNTAN. Analisis univariat dilakukan untuk melihat frekwensi dan analisis bivariat digunakan untuk melihat kekuatan hubungan dan signifikansi hubungan menggunakan korelasi Spearman. Hasil. Tiga puluh satu dokter angkatan 2005(angkatan pertama) ikut dalam penelitian ini, dengan catatan 11 dokter lulus pada bulan November 2010, 5 dokter pada bulan Januari 2011 dan 15 dokter pada bulan juni 2011. Terdapat penurunan rerata IPK dan rerata UKDI dari setiap periode. Terdapat hubungan yang signifikan dan cukup kuat antara IPK dan nilai UKDI Kesimpulan. Terdapat hubungan yang signifikan antara IPK dan nilai UKDI
\end{abstract}

Kata kunci : Indeks Prestasi, Uji Kompetensi Dokter Indonesia

\section{Pendahuluan}

Sebanyak 6.000 dokter umum diluluskan oleh fakultas kedokteran di seluruh Indonesia setiap tahun. Perlu adanya standarisasi tingkat nasional yang dapat mewakili kompetensi dokter Indonesia, maka sejak tahun 2007 diadakanlah Ujian Kompetensi Dokter Indonesia(UKDI). UKDI merupakan

${ }^{1}$ Arif Wicaksono : Dosen Fakultas Kedokteran UNTAN 
ujian tertulis yang mewakili seluruh cabang keilmuan yang dipelajari baik dalam masa pre-klinik maupun masa klinik. Tujuan UKDI adalah untuk memberikan informasi berkenaan kompetensi pengetahuan, ketrampilan, dan sikap dari para lulusan dokter umum secara komprehensif kepada pemegang kewenangan dalam pemberian sertifikat kompetensi sebagai bagian dari persyaratan registrasi, untuk kemudian seorang dokter dapat mengurus pengajuan surai ijin praktik /SIP (KBUKDI,2008).

Prodi Pendidikan Dokter FKIK UNTAN berdiri sejak tahun 2005 di Pontianak, Kalimantan Barat. Mahasiswa angkatan pertama berjumlah 45 orang dan sampai bulan mei 2011 telah meluluskan 31 orang dokter. Para dokter baru ini akan langsung menghadapi UKDI sebagai awal persyaratan mereka sebagai dokter(data primer,2011).

Indeks prestasi kumulatif (IPK) mahasiswa dianggap berperan terhadap nilai UKDI IPK merupakan cerminan kemajuan belajar mahasiswa yang mencakup pengetahuan dan keterampilan yang didapatkan di saat kuliah dan saat kepaniteraan yang sangat berguna untuk mengerjakan soal UKDI.

\section{Tujuan Penelitian}

Penelitian ini bertujuan untuk mengetahui apakah ada hubungan antara IPK dan nilai UKDI dokter lulusan UNTAN.

\section{TINJAUAN PUSTAKA}

\section{IPK}

Indeks Prestasi Kumulatif (IPK) merupakan angka yang menunjukkan prestasi atau kemajuan belajar mahasiswa secara kumulatif mulai dari semester pertama sampai dengan semester paling akhir yang telah ditempuh. IPK dihitung pada tiap akhir semester (Faperta UNPAD, 2009). Adapun rumus perhitungan IPK adalah sebagai berikut (pembulatan ke bawah apabila kurang dari 0,05 , pembulatan ke atas apabila sama/lebih dari 0,05) (Buku Panduan Akademik FKIK,2010) :

$$
\mathrm{IPK}=\frac{\mathrm{Jmlh}(\mathrm{AM} \times \mathrm{SKS}) \text { seluruh semester yang ditempuh }}{\text { Jmlh SKS seluruh semester yang ditempuh }}
$$


IPK digunakan untuk menentukan beban studi semester berikutnya. Rentang IPK dan jumlah SKS maksimum yang boleh diambil mahasiswa pada semester berikutnya adalah sebagai berikut :

Tabel 1.Rentang IPK dan jumlah SKS maksimum yang dapat diambil mahasiswa

\begin{tabular}{|l|c|}
\hline Rentang IPK & Jumlah SKS maksimum \\
\hline $3,50-4,00$ & $22-24$ \\
\hline $3,00-3,49$ & $19-21$ \\
\hline $2,50-2,99$ & $15-18$ \\
\hline $2,00-2,49$ & $12-14$ \\
\hline$<2,00$ & 11 \\
\hline
\end{tabular}

IPK digunakan sebagai kriteria untuk memberi sanksi akademik dan evaluasi studi pada akhir program.Mahasiswa diperbolehkan mengambil beban studi semesteran yang kurang dari jumlah minimal yang diperkenankan, tetapi tidak diperbolehkan mengambil beban studi semesteran yang lebih besar dari jumlah maksimal yang diperkenankan. Dengan demikian jelas bahwa IPK dapat menjadi tolok ukur kemajuan mahasiswa dan penguasaan mahasiswa mengenai suatu materi, dalam hal ini kompetensi pendidikan kedokteran(Buku Panduan Akademik FKIK,2010).

IPK cenderung tinggi di semester awal kemudian menurun di semester berikutnya karena pada semester awal masih banyak kuliah yang bersifat umum. Saat semester berikutnya terjadi penurunan yang dimungkinkan karena mata kuliah/modul yang lebih kompleks, dan adanya kepaniteraan klinik yang mengharuskan mahasiswa beradaptasi dengan lingkungan baru/rumah sakit. Berikut merupakan tabel rata-rata IPK mahasiswa PSPD UNTAN angkatan 2005 :

Tabel 2.rata-rata IPK mahasiswa PSPD UNTAN angkatan 2005

\begin{tabular}{|c|c|c|c|c|c|c|c|}
\hline \multicolumn{7}{|c|}{ RATA-RATA IPK PER SEMESTER } \\
\hline 1 & 2 & 3 & 4 & 5 & 6 & 7 & 8 \\
\hline 3,55 & 3,11 & 2,90 & 2,81 & 2,69 & 2,70 & 2,72 & 2,75 \\
\hline
\end{tabular}

Sumber : Data sekunder Akademik PSPD UNTAN ,2009 


\section{UKDI}

UKDI merupakan ujian tertulis yang mewakili seluruh cabang keilmuan yang dipelajari baik dalam masa pre-klinik maupun masa klinik. Tujuan UKDI adalah untuk memberikan informasi berkenaan kompetensi pengetahuan, ketrampilan, dan sikap dari para lulusan dokter umum secara komprehensif kepada pemegang kewenangan dalam pemberian sertifikat kompetensi sebagai bagian dari persyaratan registrasi, untuk kemudian seorang dokter dapat mengurus pengajuan surai ijin praktik (SIP) (KBUKDI,2008).

UKDI merupakan regulasi baru yang diatur dalam UU Praktik Kedokteran No 29 tahun 2004. Disebutkan di pasal 1, Sertifikat Kompentensi adalah surat tanda pengakuan terhadap kemampuan seorang dokter atau dokter gigi untuk menjalankan prektik kedokteran di seluruh Indonesia setelah lulus uji kompetensi (Sidipratomo, 2010).

Telah muncul banyak sekali perdebatan akan adanya UKDI ini tetapi Ikatan Dokter Indonesia(IDI)menyatakan tetap menjadikan uji kompetensi dokter Indonesia atau UKDI sebagai syarat mendapatkan izin praktik dokter dan perlindungan bagi pasien. Selain itu, UKDI juga diperlukan untuk mempertahankan dan meningkatkan mutu pelayanan medis yang diberikan oleh dokter dan memberikan kepastian hukum kepada masyarakat dan dokter itu sendiri( Yusuf, 2010)

UKDI dalam pelaksanaannya merupakan ujian tertulis dengan 200 soal yang harus diselesaikan dalam waktu 200 menit. Soal yang ada dalam UKDI dibuat sedemikian rupa sehingga sangat objektif dan memenuhi tinjauantinjauan berikut ini (KBUKDI,2008) :

Tabel 3. Tinjauan soal-soal UKDI

\begin{tabular}{|l|ll|}
\hline No & \multicolumn{1}{|c|}{ Tinjauan } \\
\hline 1 & Tinjauan 1 \\
& 1. & Komunikasi efektif \\
& 2. & Keterampilan dasar klinis \\
& 3. & Aplikasi biomedis, perilaku, klinis dan epidemiologi \\
& & pada kedokteran keluarga \\
& 4. & Manajemen masalah kesehatan primer \\
& 5. & Penelusuran, kritisi dan manajemen informasi \\
& 6. & Profesionalisme, moral dan etika praktik kedokteran \\
\hline
\end{tabular}




\begin{tabular}{|c|c|}
\hline & $\begin{array}{l}\text { 7. Kesadaran, pemeliharaan dan pengembangan } \\
\text { professional }\end{array}$ \\
\hline 2 & \begin{tabular}{ll}
\multicolumn{2}{l}{ Tinjauan 2} \\
1. & Kognitif \\
2. & Procedural knowledge \\
3. & Konatif
\end{tabular} \\
\hline 3 & $\begin{array}{ll}\text { Tinjauan } 3 \\
\text { 1. } & \text { recall } \\
\text { 2. } & \text { reasoning } \\
\end{array}$ \\
\hline 4 & $\begin{array}{l}\text { Tinjauan } 4 \\
\text { 1. } \text { saraf dan perilaku } \\
\text { 2. kepala dan Leher } \\
\text { 3. endokrin dan metabolisme } \\
\text { 4. } \text { saluran cerna, hepatobilier dan pancreas } \\
\text { 5. saluran pernafasan } \\
\text { 6. ginjal dan saluran kemih } \\
\text { 7. jantung, pembuluh darah dan sistem limfatik } \\
\text { 8. darah dan system pertahanan tubuh } \\
\text { 9. kulit, otot, tulang dan jaringan lunak } \\
\text { 10. reproduksi } \\
\text { 11. lain-lain }\end{array}$ \\
\hline 5 & $\begin{array}{l}\text { Tinjauan } \mathbf{5} \\
\text { 1. pertumbuhan, perkembangan dan degenerasi } \\
\text { 2. } \\
\text { 3. } \text { pelainan genetik dan kongenital } \\
\text { 4. } \text { penyakit akibat trauma atau kecelakaan } \\
\text { 5. penyakit neoplasma } \\
\text { 6. lain-lain }\end{array}$ \\
\hline 6 & $\begin{array}{l}\text { Tinjauan } 6 \\
\text { 1. } \\
\text { 2. } \text { promosi kesehatan dan pencegahan penyakit } \\
\text { 3. } \text { manajemen/terapi } \\
\text { 4. } \text { rehabilitasi } \\
\text { 5. } \\
\text { aspek hukum dan etika }\end{array}$ \\
\hline 7 & $\begin{array}{ll}\text { Tinjauan } 7 \\
\text { 1. } \\
\text { 2. } & \text { keluarga } \\
\text { 3. } & \text { masyarakat } \\
\end{array}$ \\
\hline
\end{tabular}

Sumber : KBUKDI, 2008 


\section{METODOLOGI}

Penelitian ini merupakan penelitian analitik cross sectional yang dilakukan selama bulan Agustus 2011 di Prodi Pendidikan Dokter FKIK UNTAN. Sampel dalam penelitian ini adalah sebanyak 31 orang yang memenuhi kriteria penelitian sebagai berikut :

Kriteria Inklusi

1. Masuk ke PSPD FKIK UNTAN pada tahun 2005

2. Sudah lulus menjadi dokter

Kriteria eksklusi pada penelitian ini adalah dokter yang tidak mengikuti UKDI dengan alasan apapun.

Variabel penelitian pada penelitian ini adalah IPK sebagai variabel bebas dan nilai UKDI sebagai variabel terikat

Analisis data dilakukan menggunakan SPSS 16 yang terbagi menjadi analisis univariat dan bivariat. Analisis univariat dilakukan untuk melihat frekwensi dan analisis bivariat digunakan untuk melihat kekuatan hubungan dan signifikansi hubungan menggunakan korelasi Spearman.

\section{HASIL}

\section{Analisis Univariat}

Program Studi Pendidikan Dokter (PSPD) FKIK UNTAN telah meluluskan 31 dokter sampai bulan Juni 2011 yang kesemuanya adalah mahasiswa angkatan 2005(angkatan pertama). Tiga puluh satu dokter ini lulus dalam periode yang berbeda, yaitu pada bulan November 2010, Januari 2011 dan juni 2011.

Tabel 4.IPK dan Nilai UKDI dokter lulusan bulan November 2010

\begin{tabular}{|l|l|l|c|c|}
\hline No & Dokter & $\begin{array}{c}\text { Asal Daerah } \\
\text { (ikatan dinas) }\end{array}$ & IPK & Nilai UKDI \\
\hline 1 & R & Kab. Pontianak & 3,32 & 82,5 \\
\hline 2 & IP & Kab. Pontianak & 3,1 & 77 \\
\hline 3 & HS & Kota Pontianak & 3,09 & 75,5 \\
\hline 4 & M & Kab. Sanggau & 3,07 & 77,5 \\
\hline 5 & SM & Kab. Sintang & 3,06 & 76,5 \\
\hline 6 & SAP & SPMB & 3,24 & 81,5 \\
\hline 7 & DY & SPMB & 3,11 & 82,5 \\
\hline
\end{tabular}




\begin{tabular}{|l|l|l|c|c|}
\hline 8 & BWS & SPMB & 2,93 & 68,5 \\
\hline 9 & TW & SPMB & 2,88 & 74 \\
\hline 10 & AJP & SPMB & 2,84 & 70 \\
\hline 11 & NK & SPMB & 2,72 & 73,5 \\
\hline & & Rata-rata & 3,03 & 76,23 \\
\hline
\end{tabular}

Sumber : Data primer, 2011

Tabel 4 memperlihatkan 11 dokter lulusan pertama yang terdiri dari 5 dokter ikatan dinas dan 6 dokter dari SPMB. Nilai IPK tertinggi 3,32, terendah 2,72 dengan rata-rata 3,03 . Nilai UKDI tertinggi 82,5 , terendah 68,5 dengan ratarata 76,23 .

Tabel 5. Rata-rata IPK dan Nilai UKDI dokter lulusan bulan November 2010 menurut daerah

\begin{tabular}{|l|l|c|c|}
\hline No & Daerah & $\begin{array}{l}\text { Rata- } \\
\text { rata IPK }\end{array}$ & $\begin{array}{l}\text { Rata-rata } \\
\text { UKDI }\end{array}$ \\
\hline 1 & Kab. Pontianak(2) & 3,21 & 79,5 \\
\hline 2 & Kota Pontianak(1) & 3,09 & 75,5 \\
\hline 3 & Kab. Sanggau(1) & 3,07 & 77,5 \\
\hline 4 & Kab. Sintang (1) & 3,06 & 76,5 \\
\hline 5 & SPMB(6) & 2,95 & 75 \\
\hline
\end{tabular}

Sumber : Data primer, 2011

Tabel 5 memperlihatkan rata-rata IPK dan rata-rata nilai UKDI per daerah ikatan dinasdan SPMB, terlihat bahwa rata-rata IPK dan rata-rata nilai UKDI cukup tinggi.

Tabel 6. IPK dan Nilai UKDI dokter lulusan bulan Januari 2011

\begin{tabular}{|l|l|l|c|c|}
\hline No & Dokter & $\begin{array}{l}\text { Asal Daerah } \\
\text { (ikatan dinas) }\end{array}$ & IPK & Nilai UKDI \\
\hline 1 & Mi & Kota Pontianak & 3,48 & 80,5 \\
\hline 2 & IM & Kab. Sintang & 3,01 & 77,5 \\
\hline 3 & KYAD & Kab. Sintang & 2,88 & 75,5 \\
\hline 4 & AC & Kab. Landak & 2,65 & 68 \\
\hline 5 & LR & Kab. Sekadau & 2,61 & 68,5 \\
\hline & & Rata-rata & 2,93 & 74 \\
\hline
\end{tabular}

Sumber : Data primer, 2011 
Tabel 6 memperlihatkan lima dokter lulusan kedua yang kesemuanya berasal dari ikatan dinas. Nilai IPK tertinggi 3,48, terendah 2,61 dengan ratarata 2,93. Nilai UKDI tertinggi 80,5, terendah 68 dengan rata-rata 74 .

Tabel 7. Rata-rata IPK dan Nilai UKDI dokter lulusan bulan Januari 2011 menurut daerah

\begin{tabular}{|l|l|c|c|}
\hline No & Daerah & Rata-rata IPK & Rata-rata UKDI \\
\hline 1 & Kota Pontianak(1) & 3,48 & 80,5 \\
\hline 2 & Kab. Sintang(2) & 2,95 & 76,5 \\
\hline 3 & Kab. Landak(1) & 2,65 & 68 \\
\hline 4 & Kab. Sekadau(1) & 2,61 & 68,5 \\
\hline
\end{tabular}

Sumber : Data primer, 2011

Tabel 7 memperlihatkan rata-rata IPK dan rata-rata nilai UKDI per daerah ikatan dinas, terlihat bahwa rata-rata IPK dan rata-rata nilai UKDI mengalami penurunan dari lulusan pertama.

Tabel 8. IPK dan Nilai UKDI dokter lulusan bulan Juni 2011

\begin{tabular}{|l|l|l|c|c|}
\hline No & Dokter & $\begin{array}{l}\text { Asal Daerah } \\
\text { (ikatan dinas) }\end{array}$ & \multicolumn{1}{l|}{ IPK } & Nilai UKDI \\
\hline 1 & Ma & Kab. Kapuas Hulu & 2,59 & 68,5 \\
\hline 2 & EH & Kab. Kapuas Hulu & 2,57 & 66 \\
\hline 3 & RK & Kab. Kapuas Hulu & 2,52 & 63 \\
\hline 4 & YA & Kab. Ketapang & 3,16 & 66,5 \\
\hline 5 & CS & Kab. Ketapang & 2,78 & 71 \\
\hline 6 & YYE & Kab. Sanggau & 2,49 & 71,5 \\
\hline 7 & YRR & Kab. Sanggau & 2,44 & 56,5 \\
\hline 8 & RP & Kab. Sambas & 3,01 & 75,5 \\
\hline 9 & MTL & Kab. Bengkayang & 2,93 & 72 \\
\hline 10 & DA & Kab. Sekadau & 2,69 & 61,5 \\
\hline 11 & Mu & Kab. Melawi & 2,68 & 62 \\
\hline 12 & PS & Kab. Landak & 2,42 & 65,5 \\
\hline 13 & AD & SPMB & 2,99 & 68,5 \\
\hline 14 & ISH & SPMB & 2,95 & 74,5 \\
\hline 15 & HWK & SPMB & 2,46 & 61,5 \\
\hline & & Rata-rata & 2,71 & 66,93 \\
\hline
\end{tabular}

Sumber : Data primer, 2011 
Tabel 8 memperlihatkan 15 dokter lulusan ketiga yang terdiri dari 12 dokter ikatan dinas dan 3 dokter dari SPMB. Nilai IPK tertinggi 3,16, terendah 2,42 dengan rata-rata 2,71 . Nilai UKDI tertinggi 75,5, terendah 56,5 dengan ratarata 66,93 .

Tabel 9. Rata-rata IPK dan Nilai UKDI dokter lulusan bulan Juni 2011 menurut daerah

\begin{tabular}{|c|c|c|c|}
\hline No & Daerah & $\begin{array}{l}\text { Rata-rata } \\
\text { IPK }\end{array}$ & Rata-rata UKDI \\
\hline 1 & Kab. Kapuas Hulu (3) & 2,56 & 65,83 \\
\hline 2 & Kab. Ketapang (2) & 2,97 & 68,75 \\
\hline 3 & Kab. Sanggau(2) & 2,47 & 64 \\
\hline 4 & Kab. Sambas (1) & 3,01 & 75,5 \\
\hline 5 & Kab. Bengkayang (1) & 2,93 & 72 \\
\hline 6 & Kab. Sekadau(1) & 2,69 & 61,5 \\
\hline 7 & Kab. Melawi(1) & 2,68 & 62 \\
\hline 8 & Kab. Landak(1) & 2,42 & 65,5 \\
\hline 9 & SPMB(3) & 2,8 & 68,17 \\
\hline
\end{tabular}

Sumber : Data primer, 2011

Tabel 9 memperlihatkan rata-rata IPK dan rata-rata nilai UKDI per daerah ikatan dinas dan SPMB, terlihat bahwa rata-rata IPK dan rata-rata nilai UKDI mengalami penurunan dari lulusan kedua. Tabel 4.7 dibawah ini memperlihatkan rekapitulasi rata -rata IPK dan Nilai UKDI dokter lulusan UNTAN menurut daerah.

Tabel 10.Rekapitulasi Rata-rata IPK dan Nilai UKDI dokter lulusan UNTAN menurut daerah

\begin{tabular}{|l|l|c|c|}
\hline No & \multicolumn{1}{|c|}{ Daerah } & Rata-rata IPK & Rata-rata UKDI \\
\hline 1 & Kab. Kapuas Hulu (3) & 2,56 & 65,83 \\
\hline 2 & Kab. Sintang (3) & 2.98 & 76,5 \\
\hline 3 & Kab. Sanggau(3) & 2,67 & 68,5 \\
\hline 4 & Kota Pontianak(2) & 3,29 & 78 \\
\hline 5 & Kab. Pontianak (2) & 3,21 & 79,5 \\
\hline 6 & Kab. Ketapang (2) & 2,97 & 68,75 \\
\hline
\end{tabular}




\begin{tabular}{|l|l|c|c|}
\hline 7 & Kab. Sekadau(2) & 2,65 & 65 \\
\hline 8 & Kab. Landak(2) & 2,54 & 66,75 \\
\hline 9 & Kab. Melawi(1) & 2,68 & 62 \\
\hline 10 & Kab. Sambas (1) & 3,01 & 75,5 \\
\hline 11 & Kab. Bengkayang (1) & 2,93 & 72 \\
\hline 12 & SPMB(9) & 2,9 & 72,72 \\
\hline
\end{tabular}

Sumber : Data primer, 2011

Dua Grafik dibawah ini menunjukkan perjalanan rata-rata IPK dan rata-rata nilai UKDI dokter lulusan UNTAN selama tiga kali kelulusan. Grafik memperlihatkan bahwa terjadi penurunan di kedua bidang ini.

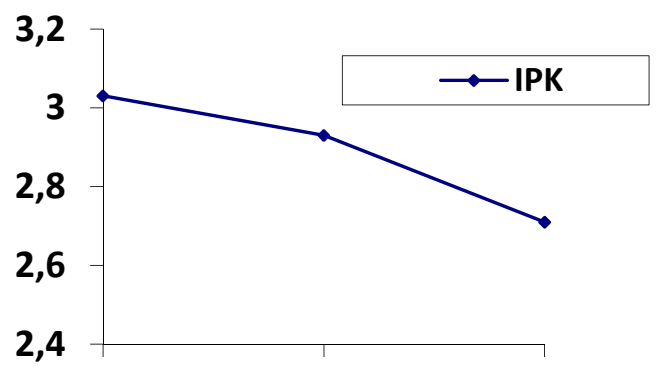

\section{Iulusan 1 lulusan 2 lulusan 3}

Grafik 1. Rata-rata IPK dokter lulusan UNTAN

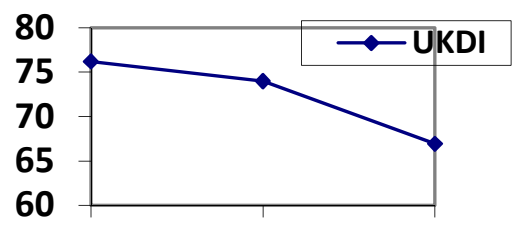

Iulusan lulusan lulusan

1

2

3

Grafik 2. Rata-rata nilai UKDI dokter lulusan UNTAN

\section{Analisis Bivariat}

Hubungan antara IPK dan nilai UKDI dokter lulusan UNTAN dianalisis menggunakan korelasi spearman (Sugiyono,2005). Korelasi 
digunakan untuk melihat kuatnya hubungan antara dua variabel atau lebih. Hubungan bisa positif dan negatif. Hubungan positif berarti semakin tinggi satu variabel, variabel lain juga makin tinggi. Hubungan negatif(-) berarti semakin tinggi satu variabel, variabel lain semakin rendah atau sebaliknya. Hasilnya adalah 0,591(Sarwono,2009). Angka korelasi bervariasi dari -1 sampai 1(positif 1). Angka -1 atau 1 menunjukkan hubungan yang sangat kuat atau sempurna dari variabel yang diteliti(Sugiyono,2005). Angka korelasi 0,591 menunjukkan bahwa ada hubungan yang cukup kuat antara IPK dan nilai UKDI dokter lulusan UNTAN.

Signifikansi hubungan antara IPK dan nilai UKDI dokter lulusan UNTAN adalah 0,01(<0,05) (Sarwono,2009). Angka ini menunjukkan bahwa ada hubungan yang sangat bermakna antara IPK dan nilai UKDI dokter lulusan UNTAN.

\section{KESIMPULAN}

1. Terdapat hubungan yang sangat bermakna antara IPK dan nilai UKDI dokter lulusan UNTAN.

2. kekuatan hubungan antara IPK dan nilai UKDI dokter lulusan UNTAN cukup kuat

3. Terjadi penurunan IPK dan nilai UKDi dokter lulusan UNTAN selama tiga periode kelulusan

\section{REFERENSI}

1. Faperta UNPAD. 2009. Indeks Prestasi Kumulatif. UNPAD. Bandung.

2. KBUKDI. 2008. Ujian Kompetensi Dokter Indonesia. KBUKDI. Jakarta

3. Sarwono, J. 2009. Statistik itu Mudah. ANDI. Yogyakarta.

4. Sidipratomo, P. 2010. Tanpa UKDI Bermimpilah Jadi Dokter. Kompas. Jakarta

5. Sugiyono. 2005. Statistika untuk Penelitian.Alfabeta. Bandung.

6. Tim Penyusun . 2009. Buku panduan Akademik. FKIK UNTAN. Pontianak

7. Yusuf, I. 2010. Ujian Kompetensi Dokter Indonesia .PosKota. Jakarta 